\title{
INTEGRATING LASER SCANNER AND BIM FOR CONSERVATION AND REUSE: "THE LYRIC THEATRE OF MILAN"
}

\author{
G. Utica ${ }^{1}$, L. Pinti ${ }^{1}$, L. Guzzoni $^{1}$, S. Bonelli ${ }^{2}$, A. Brizzolari ${ }^{2}$ \\ ${ }^{1}$ Polytechnic of Milan, Department of Architecture, Built Environment and Construction Engineering, \\ Via Ponzio 31, 20133 Milan, Italy - (gianni.utica, lidia.pinti, luigi.guzzoni) @ polimi.it \\ ${ }^{2}$ Polytechnic of Milan, Department of Architecture, Built Environment and Construction Engineering, \\ Via Ponzio 31, 20133 Milan, Italy - (serena.bonelli, alessandra1.brizzolari) @ mail.polimi.it
}

\author{
Commission V, WG V/7
}

\begin{abstract}
KEY WORDS: Building Information Modelling (BIM), Work Breakdown Structure (WBS), Laser Scanner, Conservation and
\end{abstract} Reuse, Lyric Theatre, Historical Building

\begin{abstract}
:
The paper underlines the importance to apply a methodology that integrates the Building Information Modeling (BIM), Work Breakdown Structure (WBS) and the Laser Scanner tool in conservation and reuse projects. As it is known, the laser scanner technology provides a survey of the building object which is more accurate rather than that carried out using traditional methodologies. Today most existing buildings present their attributes in a dispersed way, stored and collected in paper documents, in sheets of equipment information, in file folders of maintenance records. In some cases, it is difficult to find updated technical documentation and the research of reliable data can be a cost and time-consuming process. Therefore, this new survey technology, embedded with BIM systems represents a valid tool to obtain a coherent picture of the building state. The following case consists in the conservation and reuse project of Milan Lyric Theatre, started in 2013 from the collaboration between the Milan Polytechnic and the Municipality. This project first attempts to integrate these new techniques which are already professional standards in many other countries such as the US, Norway, Finland, England and so on. Concerning the methodology, the choice has been to use BIM software for the structured analysis of the project, with the aim to define a single code of communication to develop a coherent documentation according to rules in a consistent manner and in tight schedules. This process provides the definition of an effective and efficient operating method that can be applied to other projects.
\end{abstract}

\section{INTRODUCTION}

One of the most important element in managing the built environment, is linked to the relationship between action and knowledge. Only with a deep knowledge of the real estate assets it is possible to enhance, manage and make building adequate to the users' needs, reaching quality goals, following efficiency and costs saving principles. Therefore, all the actors that intervene in the building life cycle need a certain level of asset knowledge according to their assignments. In fact, the acquisition of a complete set of data represents the fundamental condition which permits a correct development of all the activities that are linked to buildings. Required data are related to the object itself, so to the building and its parts, including geometrical but also descriptive information. Concerning this need of knowledge, it is possible to highlight the fact that in Italy there is a diffused shortage of attention towards conservation and transmission of information on existing buildings. The prevalent tendency consists in storing data in a disorganised way, without any transmission and conservation of documents and therefore with dispersion of useful information for the correct knowledge of the building and its components.

It is clear that finding efficient ways to gather, access and update this information, is very important.

Most existing buildings show this data stored and collected in paper documents like rolls of drawings for the architects and engineers, sheets of equipment information for each type of plants, file folders of maintenance records.
This documentation is usually contractually requested by the owner and is handed over after the building is already in use; normally this happens months later and data are collected in some basement offices where it is difficult to access. So, the challenge of improving and standardizing the quality of information is a key aspect to meet day to day operational needs, providing reliable data for life cycle management.

In this context, the birth of new technologies such as Laser Scanner combined with Building Information Modeling can be a powerful tool to optimize the process, providing accurate data in less time. In this way, the problems affecting survey, design and construction of existing buildings can be overcome. The laser scanner technique adds its value especially in restoration projects including cultural heritage, when shapes and geometry are quite different and complex.

Moreover, the 3D laser scanner generates digital documentation of buildings, individual objects and complex environments and sites, also reaching inaccessible areas. Then the cloud points, which is the final product of a laser scanner survey can be used to create a BIM model in a virtual environment. So, the integration of a laser scanner survey and Building Information Modelling for managing-acting on the built environment can be an opportunity.

This is the case of the Lyric Theatre which has been developed till the working plan level, taking advantage of the laser scanner precise survey to develop the overall procedure with Building Information Modeling. The use of both these technologies 
improves the building process by reducing the margin of error and facilitating the exchange of information between all the players involved.

In particular, the method has been developed according to the following steps.

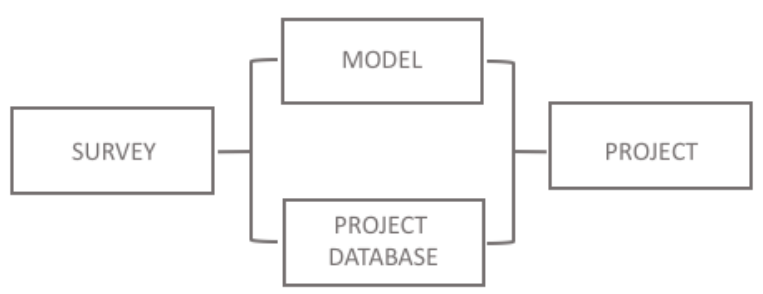

Figure 1 . The process by steps

After the initial survey conducted through the laser scanner, we proceed to the creation of the three-dimensional model and to the definition of a communication code based on normed classification plans. By appropriately characterizing the model with the information derived from the database, a BIM model that faithfully reproduces the project, is created (Figure 1). The next step is the preparation of the project documentation required.

\section{FIRST PHASE: SURVEY VIA LASER SCANNER}

The 3D laser scanning is becoming more powerful during the recent years especially in the As-Built field. It represents an efficient tool to obtain a precise picture of a real object/environment because it is able to measure fine details, to capture a variety and complexity of shapes generating exact point clouds. This method accelerates the standard procedure of acquiring massive amount of data to describe certain surfaces and geometries; it facilitates the survey and the graphical result of spaces where doing this is impractical with the use of traditional measurement methods.

The Laser Scanner technology allows the remote detection of the morphology of an architectural structure, through a laser which strikes the surface to be detected, leaving a point as the trace. Therefore, it is clear that these capabilities in a context of a particular object to be surveyed as the Lyric Theatre are really favourable.

As a non-destructive technology, 3D laser scanning launches its beam from several stations in which the tool is placed, to the surfaces of the building. The 3D laser scanner is targeted to the physical objects to be scanned and the laser beam is directed over the object in a closely spaced grid of points. By measuring the time of laser flight, which is the time of travel of the laser from the scanner to the physical objects and back to the scanner, the position in three-dimensional space of each scanned point on the object is established. The first result is a "cloud of points" which consists in thousands of points in 3-dimensional space that are a dimensionally accurate representation of the existing object. The cloud points generated to represent each element and surface can have different densities, measured in number of points, according to the scanner settings, to the level of precision requested and to its final use in design or construction.

Even if the survey activities can be quickly performed by a staff with adequate experience, however, attention must be paid during the analysis, the processing and the modeling of the data from the laser scanner. In particular, the point clouds can be often characterized by the presence of interferences, which must be deleted through special techniques before starting with the manipulation of the data. In fact, a detailed setting can detect also negligible objects as cars on a road, trees, people, outdoor and indoor furniture which can significantly weight in managing the cloud. Then, the point clouds can be manipulated through specific software that are capable of visualizing it or to extract portions useful to re-elaborate the model within the suitable applications.

For the Lyric Theatre case, preliminary activities consist of the placement of adequate targets on floors and walls. The scanner is located on a tripod $1.80 \mathrm{mt}$ high w.r.t the horizontal plan. Different measuring stations allow to detect both the exterior and the interior of the Theatre, creating a point clouds that formed the basis for BIM restitution. Around 595 stations were created (35 outdoor, 560 indoor) with an overall cloud dimension of 6,5 billion points (Figure 2). Within this cloud, every point is georeferenced with $\mathrm{x}, \mathrm{y}$, and $\mathrm{z}$ coordinates, in this way it is possible to make sections, surveys and measurements of the current condition directly from the cloud. Furthermore, with this method, it was possible to have a first picture of the textures and states of the Theatre finishes (Figure 3).

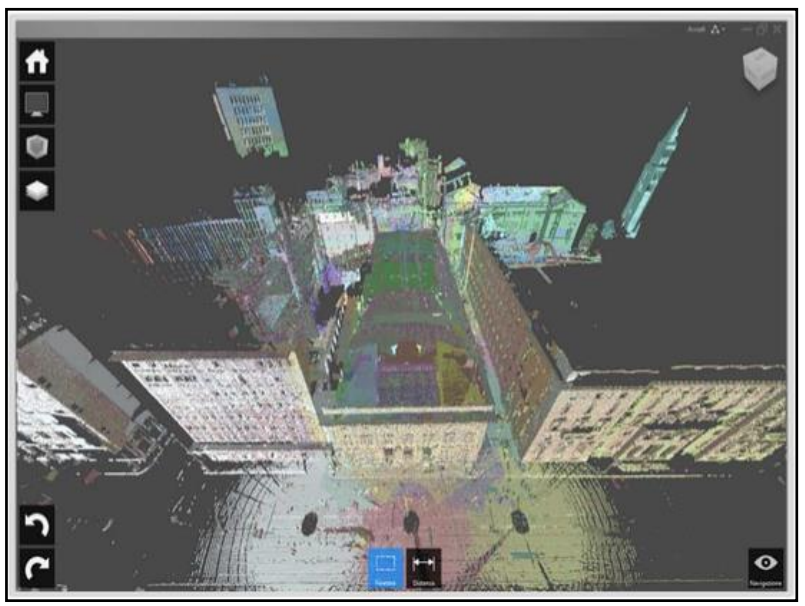

Figure 1. Point cloud of the exterior of the Lyric Theatre Source: Municipality of Milan

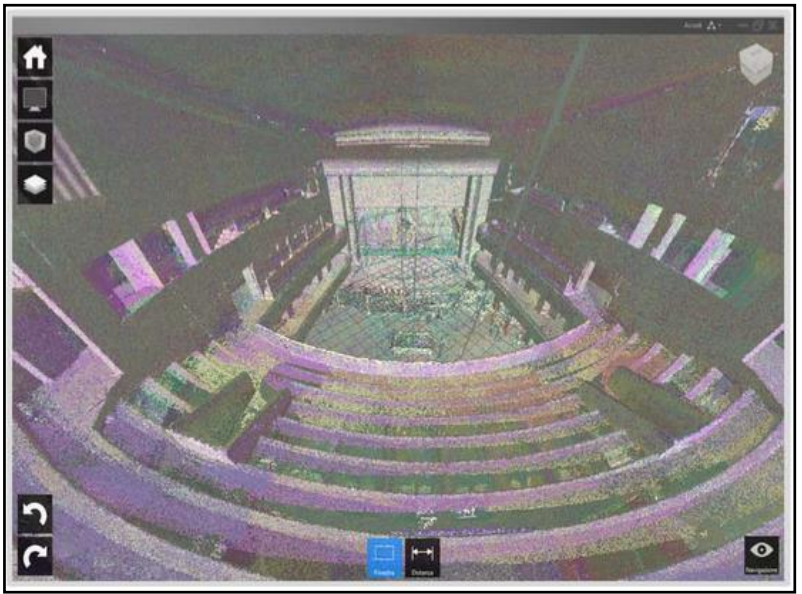

Figure 2. Point cloud of the interior of the Lyric Theatre Source: Municipality of Milan 


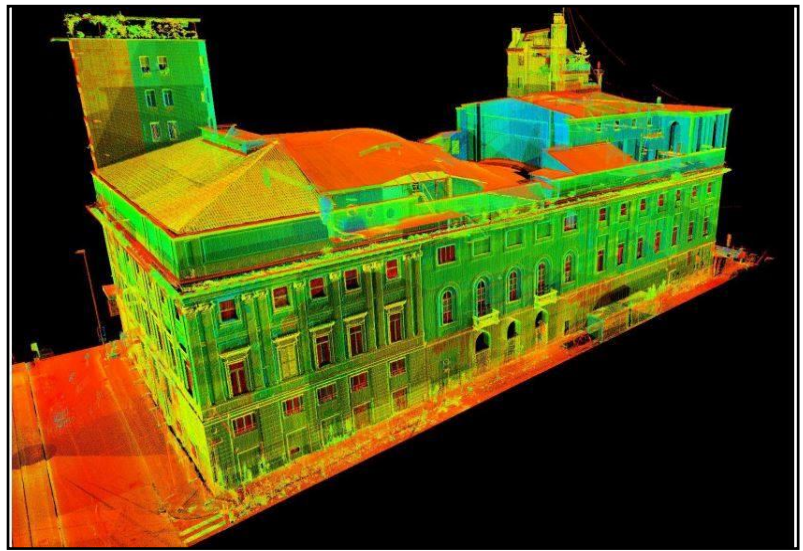

Figure 4. Overall Lyric Theatre point cloud Source: Municipality of Milan

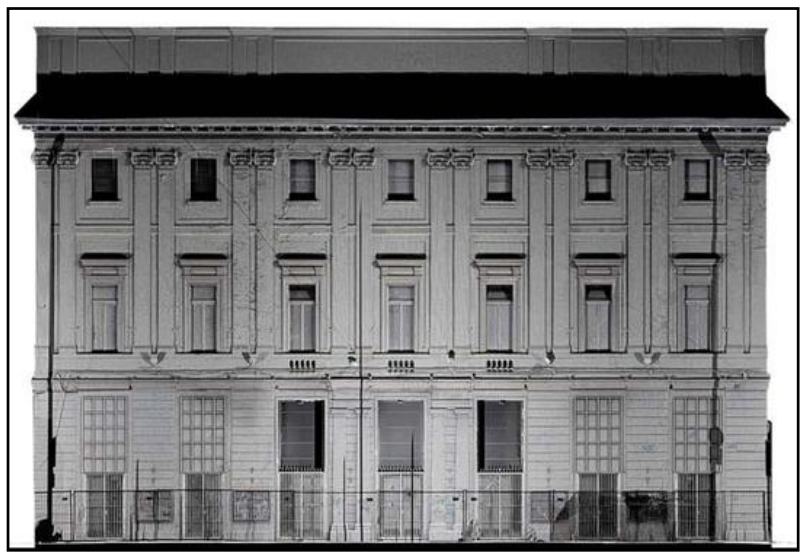

Figure 5. Point cloud of the front of the Lyric Theatre Source: Municipality of Milan

Furthermore, concerning the Lyric Theatre, architectural objects have a very complex shape and one scan is not enough to obtain the complete description of the scene (Figure 4). In these cases, there could be shaded areas, which can be deleted adding more scans taken from different points of view of the same object or they can be extracted using pictures of the elements. As we see in Figure 5, the ledge on the facade of the Theatre on Via Larga has a black band as well as for decorative elements. Therefore, to solve this problem, the laser was taken from several stations and the cloud has been integrated with manual and photographic surveys taken directly on-site. Then, the next step was the graphic restitution of the As-Built status through the interaction between the point cloud and the Building Information Modeling software. In order to support the cloud manipulation and to facilitate the import within the BIM application, it is split in sections and parts (Figure 6).

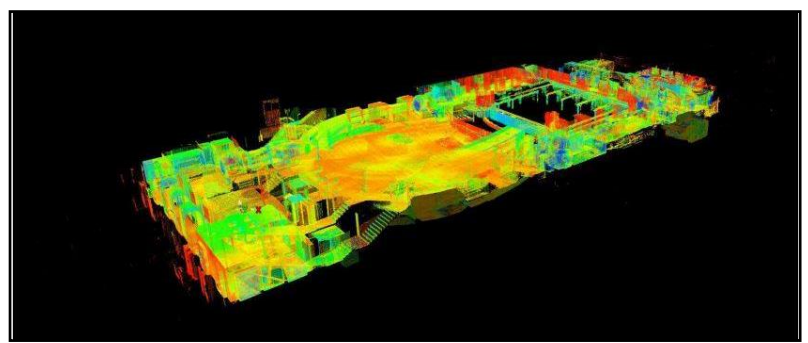

Figure 6. Point cloud section of the Lyric Theatre floor Source: : Municipality of Milan
In particular, it is divided into bodies and floors to create the walls plant profile for modelling the building (Figure 7). Then, the obtained track with a limited number of points w.r.t the total floor, can be inserted into the BIM software through appropriate commands and used as the starting point for the following phase.

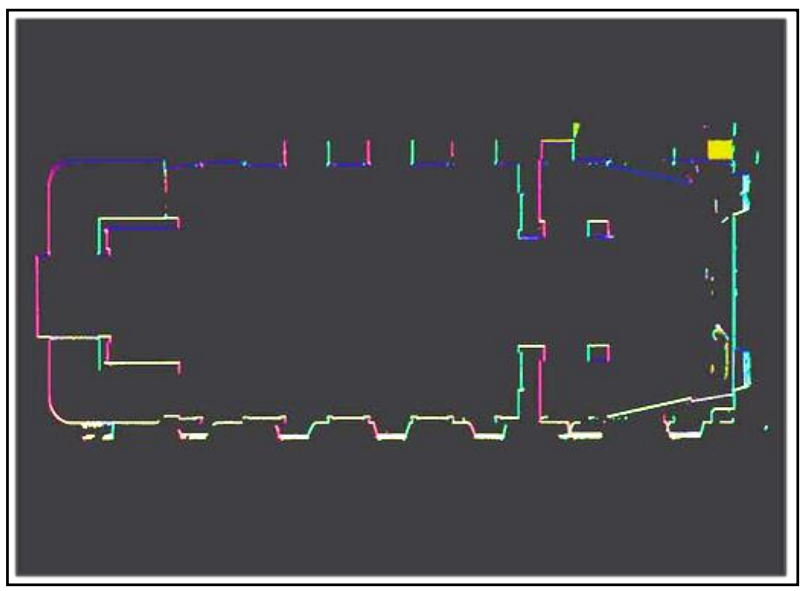

Figure 7. Plan track obtained from the point cloud Source: Municipality of Milan

\section{SECOND PHASE: 3D MODEL}

Within the BIM software it was possible to use the track just created to define the geometry of the model thus going to highlight the dimensions of the walls (Figure 8).

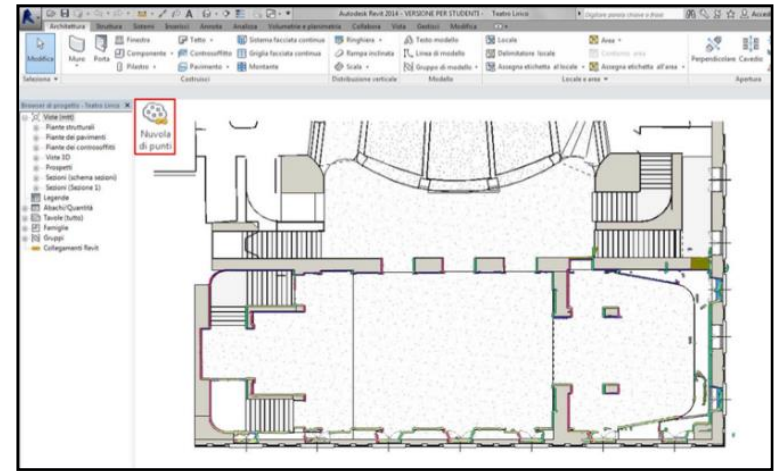

Figure 8. Plan created from the point cloud in BIM software Source: Municipality of Milan

The software allows to define walls, slabs, ceilings, roofs, windows through the use of parametric families which virtually represent the building components of the real world. The combination of all these objects determines the model. At this point, selecting a wall inside a room of the Theatre, we see that at the moment it contains only geometric information. The same thing happens for example for floors, as well as for all families described previously. Subsequently, materials that characterize rooms throughout the theatre, were defined. In fact, the first generic walls and floors, now present details about finishing materials. 


\section{THIRD PHASE: DATABASE}

The third phase was characterized by the setting up of a project database that represents a communication code common to all the actors involved in the process. This was made possible through a hierarchical top-down approach, or a Work Breakdown Structure (WBS), that becomes the key to coordinate and manage all the project documentation. To create the database, we start with a treelike graphic representation of a generic WBS already established for new construction projects, based on classification plans regulated as UNI 8290 (Italian standard) implemented by Uniformat II (ASTM E 1557-97).

This, however, was insufficient to outline all the items related to the restoration and conservation project. Therefore, the database was optimized by inserting new levels to meet all the project needs (Figure 9).

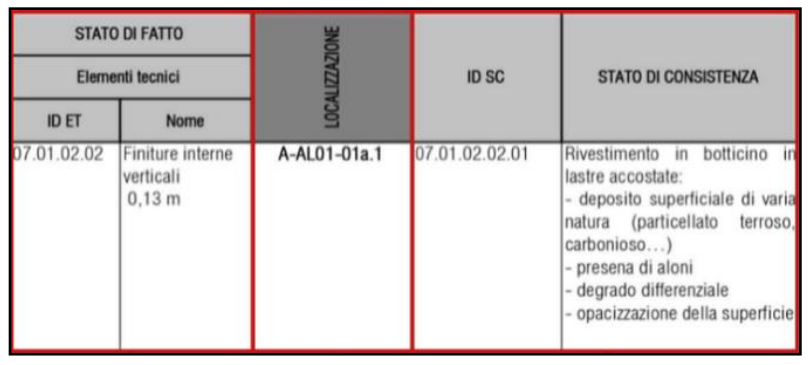

Figure 9. Information added to the generic WBS

Specifically, a level was added that identifies the current condition the technical elements, one that identifies the location, and finally one that defines the state of consistency.

For the geographic identification of technical elements, a localisation code was required to specify 4 main zones in which the theatre is divided:

- C - Dressing rooms / hygienic services;

- $\mathrm{T}$ - Stage tower;

- $\quad$ S - Theatre hall;

- A - Forepart

According to this system, it is possible to identify the body, for example the forepart (letter A) highlighted in Figure 10 with the red colour and going into more detail, the floor level (number AL01) and finally the room (01a). For individual room, the horizontal and vertical surfaces were then differentiated through a unique identification code.

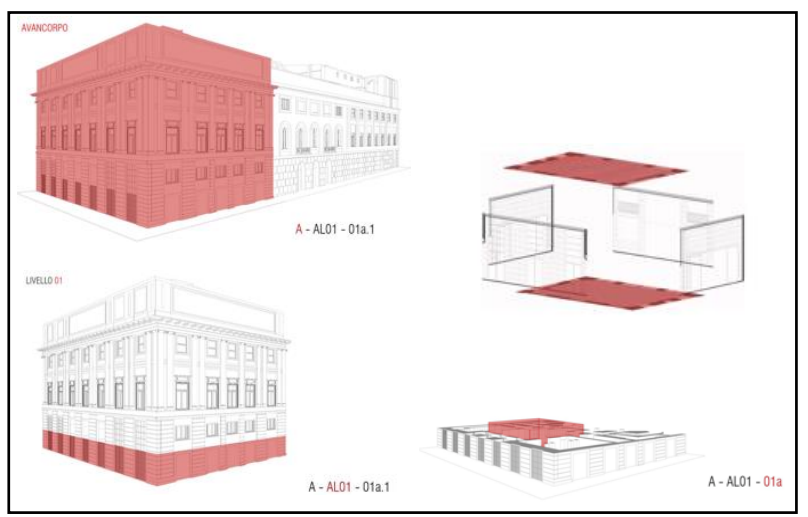

Figure 10. Classification of the forepart of the Lyric Theatre
The localisation process was fundamental to describe the consistency state and the level of existing degradation, that is specific for each identified surface. In fact, by analysing any vertical wall, there were different materials and, on the same material, also different consistencies with localised pathologies. This information is encoded and transferred within the model and the attached codes corresponds to a set of work items.

The processes (work items) are the price items extracted from the price list of the Municipality of Milan which, given the particular circumstances, in some situations have required the construction of specific prices. In these situations, it has been necessary to use the pricing analysis that, in accordance with Article 32 of the Regulation (DPR 207/2010), inserts specific price items which produce a series of fact sheets that could be a source of information for possible future works.

\section{FOURTH PHASE: BIM MODEL}

The development of the three-dimensional model and the design of the project database are the fundamental steps to get to the real operative phase. In the case of a restoration project and with regards to Building Information Modeling, it is necessary that the model does not contain only geometrical information, but presents also information of a specific nature, which come from our project database that is the unique source of data.

For new construction projects the fourth level of WBS which identifies the technical elements corresponds to the BIM family, while the fifth level which is the that of work results is associated to BIM materials.

For conservation project is not possible to use only these properties, but they need to be implemented with shared parameters: customizable fields that can be created within the software, transferred to text files and recalled whenever they are needed. Within the BIM model, shared parameters are transformed into editable fields in the properties interface.

Thus, the wall that previously had only information related to its coverings, now also contains information on localisation and state of consistency, work items and price list codes.

\section{FIFTH PHASE: DOCUMENTATION}

The drafting of project documentation starts from the elaboration of the graphic model, characterized by all the information, which automatically generates a set of data that the software then grouped in tables called abacus.

The BIM models allow the construction of abacus showing the data characteristic of the project, which can be geometric in nature or prepared using simple algebraic operations. Abacus can be arranged according to fields, filters and sorts, to select and appropriately organize the data. The characterization of the model involves typing information as:

- location;

- deterioration state of materials;

- $\quad$ works to be performed on the given material;

- the price list codes of the municipality of Milan 
The abacus can contain different information depending on the documents that need to be produced; spreadsheets are organized in rows and columns, containing alphanumeric data and can perform simple algebraic operations. For more complex operations the abacus can be extracted in txt format and edited in Excel (Figure 11).

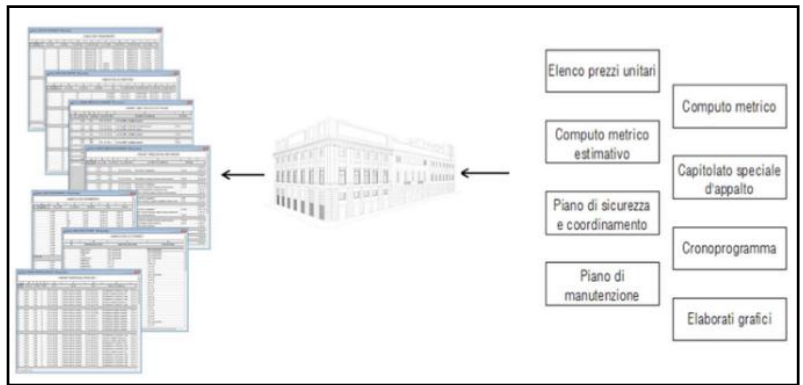

Figure 11. Workflow from BIM model to documentation

In this way the BIM model is able to develop the project documentation in compliance with the regulation:

- $\quad$ unit price list;

- $\quad$ quantity take off;

- $\quad$ bill of quantity;

- $\quad$ specification tables;

- technical data sheet;

- time schedule;

- $\quad$ maintenance plan;

- user manual;

- service manual;

- maintenance schedule; performance; subprogram of the inspections; subprogram of the tasks;

- drawings;

and if necessary a Raumbuch composed by:

- $\quad$ operative tables for rooms (Figure 12);

- $\quad$ box view of the room (Figure 13).

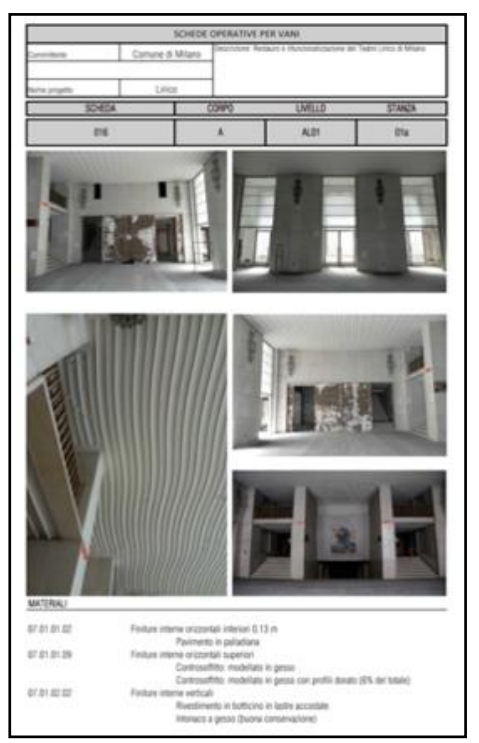

Figure 12. Example of operative table for room

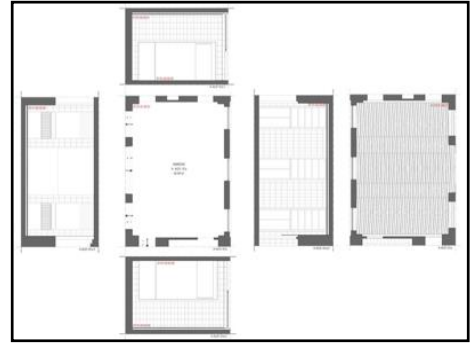

Figure 13. Example of box view of the room

\section{CONCLUSIONS}

In conclusion this case underlines which are the advantages and correlated results of 3D Laser Scanner Technology and Building Information Modeling integration. In particular,it is a noncontact, non-destructive technology that digitally captures the shape of physical objects in a faster and more accurate way w.r.t. standard methodologies. In fact, this reduces the field-time and allows surveyors to concentrate more on what the data means than on the data collection itself. Moreover, 3D laser scanners appear in a variety of platforms and types on the market, supporting flexibility in the choice of the most suitable application. Therefore, starting from a detailed survey made with a laser scanner that allows you to generate an accurate threedimensional model and, associating it with a WBS optimized for requalification works, you can get to a BIM model that permits the management of the entire project documentation in a consistent and coherent manner.

The combination of Laser scanner technology with Building Information Modelling can support a valuable process in which data geometrical and spatial first, and then descriptive, can be collected - organized - processed to reach the specific design level required. A unique database guarantees the quality of the outcome, thanks to a direct link between shapes, information and project documentation.

With this methodology that uses 3D Laser Scanner and Building Information Modeling, it is possible to achieve:

- A faster and accurate survey

- A consistent 3D survey w.r.t. the As Built condition

- A precise model on the basis of the point cloud resulting from the 3D Laser scanner technology

- consistency of the entire project documentation because it arises from a single database;

- $\quad$ responsiveness to all the criteria to be met during the verification and validation phase; 


\section{REFERENCES}

\section{Books}

Cassi Ramelli A., La ricostruzione del Teatro Lirico: 15 maggio 1938-XVI - 11 maggio 1939-XVII, Milano: Tip. Rozza di Corbella, stampa 1939

Cappochin S., Torre A., Recupero edilizio e restauro. Sei casi di utilizzo del sistema Building Information Modeling per la progettazione di interventi su edifici da ristrutturare e di valore storico. Tutte le istruzioni per ottenere il controllo della tridimensionalità, delle varianti in corso d'opera e per attuare la revisione istantanea, Milano, Il Sole24Ore, 2006.

Cappochin S., Torre A., Recupero edilizio e restauro. Sei casi di utilizzo del sistema Building Information Modeling per la progettazione di interventi su edifici da ristrutturare e di valore storico. Tutte le istruzioni per ottenere il controllo della tridimensionalità, delle varianti in corso d'opera e per attuare la revisione istantanea, Milano, Il Sole24Ore, Milano, 2010.

Eastman C. M., BIM handbook: a guide to building information modeling for owners, managers, designers, engineers, and contractors, Hoboken, Wiley, 2011.

Eastman C. M., Building Product Models: Computer Environments, Supporting Design and Construction, CRC Press, 1999.

Franceschi E., Germani L., Manuale operativo per il restauro architettonico: metodologie di intervento per il restauro e la conservazione del patrimonio storico, Roma, Dei, 2010.

Lopez G., Pintorno G., Capitolato normale per l'appalto dei regi teatri alla Scala ed alla Canobbiana di Milano (1864), Palazzo Sormani 2002.

Petracchi A. Sul reggimento dei pubblici teatri: idee economiche applicate praticamente agl'II. RR. Teatri alla Scala ed alla Canobbiana in Milano, Tipografia G. Ferrario, 1821.

Utica G., Contabilità dei lavori, Dogana (Repubblica di San Marino), Maggioli Editore, 2008.

3D Laser Scanning for Heritage (second edition), Advice and guidance to users on laser scanning in archaeology and architecture.

\section{Papers}

Alba M., Scaioni M., Comparison of techniques for terrestrial laser scanning data georeferencing applied to 3-d modelling of cultural heritage, January 2007.

Barlish K., Sullivan K., How to measure the benefits of BIM - A case study approach, in Automation in Construction, 2012, Vol. 24, pp. 149-159.

Barazzetti L., Banfi F., Brumana R., Gusmeroli G., Oreni D., Previtali M., Roncoroni F., Schiantarelli G., BIM from laser clouds and finite element analysis: Combining structural analysis and geometric complexity, The International Archives of the Photogrammetry, Remote Sensing and Spatial Information Sciences, Volume XL-5/W4, 2015, 3D Virtual Reconstruction and Visualization of Complex Architectures, 25-27 February 2015, Avila, Spain.

Ciribini A. L. C., Ventura S. M., and Paneroni M., BIM methodology as an integrated approach to heritage conservation management, WIT Trans. Built Environ., vol. 149, pp. 265-276, 2015
Golparvar-Fard M., Peña-Mora F., and Savarese S., Automated Progress Monitoring Using Unordered Daily XXXII ${ }^{\circ}$ cycle Milestone 1 State of the art Construction Photographs and IFCBased Building Information Models, J. Comput. Civ. Eng., vol. 29, no. 1, p. 4014025, 2015.

Iliescu M. and Ciocan R., Modern Technologies Innovation in Use for Quality Control on Construction Site, in Procedia Engineering, vol. 181, 2017, pp. 999-1004.

Oreni D., Brumana R., Cuca B., Towards a methodology for 3D content models. The reconstruction of ancient vaults for maintenance and structural behavior in the logic of BIM management, Digital Cartographic Heritage in service to the society: landscape analysis and informed decision making, VSMM ' 12 Int. Society on Virtual Systems and MultiMedia, 2012, pp.1-8.

Oreni D., Brumana R., Georgopoulos A., Cuca B., HBIM for conservation and management of built heritage: towards a library of vaults and wooden beam floors, Editore: ISPRS Annals of the Photogrammetry, Remote Sensing and Spatial Information Sciences, Volume II-5/W1, 2013, XXIV International CIPA Symposium, 2 - 6 September 2013, Strasbourg, France.

Park J. and Cai H., WBS-based dynamic multi-dimensional BIM database for total construction as-built documentation, Automation Construction, vol. 77, pp. 15-23, 2017.

Park H. S., Lee H. M., Adeli H., and Lee I., A new approach for health monitoring of structures: Terrestrial laser scanning, Comput. Civ. Infrastruct. Eng., vol. 22, no. 1, pp. 19-30, 2007.

Xiong X., Adan A., Akinci B, Huber D.,Automatic creation of semantically rich 3D building models from laser scanner data, in Automation in Construction, 2013, Vol. 31, 325-337.

Yen K. S., Akin K., Ravani B., and Lasky T. A., Accelerated Project Delivery: Case Studies and Field Use of 3D Terrestrial Laser Scanning in Caltrans Projects: Phase I - Training and Materials, 2011.

C. Zhang, D. Arditi, and Z. Chen, Documentation and visualization of an as-built tunnel by combining 3D laser scanning and web mapping, Int. Arch. Photogramm. Remote Sens. Spat. Inf. Sci. - ISPRS Arch., vol. XL-2/W2, no. November, pp. 139-144, 2013.

\section{Other Literature}

UNI (Ente Nazionale Italiano di Normazione), UNI 8290, Edilizia residenziale sistema tecnologico - classificazione e terminologia.

UNIFORMAT II, Elemental Classification for Building Specifications, Cost Estimating, and Cost Analysis.

Gleason D., Laser Scanning for an Integrated BIM, Lake Costance 5D-Conference 2013, Costance, 28th-29th of October.

\section{Websites}

https://content.historicengland.org.uk/images-

books/publications/3d-laser-scanning-

heritage2/3D Laser Scanning final low-res.pd

www.comunedimilano.it 